\title{
O cuírlombo da palaura: aquilombamento queer na poesia de tatiana nascimento
}

\author{
Queerlombo of word: tatiana nascimento's queer \\ and black poetry
}

\author{
Alice de Barros Gabriel \\ Doutoranda pelo PPGFil UnB / \\ professora do Instituto Federal \\ de Goiás \\ alice.gabriel@ifg.edu.br \\ https://orcid.org/0000-0001- \\ 7051-4291
}

Juliely Nóbrega dos Santos

Técnica em Análises Clínicas pelo Instituto Federal de Goiás

julielynobrega@gmail.com

https://orcid.org/0000-00026972-9161

Recebido em:07/09/2020

Aceito em:14/10/2020

\section{RESUMO}

O presente texto pretende discutir o cuirlombismo na poesia de tatiana nascimento como proposta afrofuturista. Para isso, o texto segue mostrando como os passos de tatiana vem de longe, seguindo as pegadas de Beatriz Nascimento e Abdias Nascimento, uma linhagem interpretativa que entende o quilombismo em seu laço íntimo com o passado e o futuro de pessoas negras.

Palavras-chave: Quilombo. Cuírlombo. Literatura LGBTQI. Poesia lesbiana negra.

\section{ABSTRACT}

This text aims to discuss cuirlombism in tatiana nascimento's poetry as an Afro-Futurist proposal. For that, the text continues showing how Tatiana's steps come from afar, following in the footsteps of Beatriz Nascimento and Abdias Nascimento, an interpretive lineage that understands quilombism in its intimate bond with the past and future of black people.

Keywords: quilombo. Cuirlombo. LGBTQI literature. Black lesbian poetry 


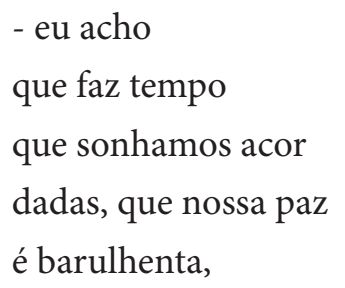

y que da areia dos nossos olhos insones

a noite fabrica suas pérolas (de

amor, e de outras guerras):

\author{
\& elas brilham \\ como nós.
}

[trecho de o amor é uma tecnologia de guerra (cientistas sub notificam arma-biológica) indestrutível, de tatiana nascimento]

\title{
Poesia não é luko
}

Audre Lorde nos conta num texto chamado Poesia não é luxo que "é pela poesia que nós damos nome àquelas ideias que estão - até o poema - inominadas e desformes, ainda por nascer, mas já sentidas" (LORDE, 2013). É um início adequado a presente empreitada. Primeiro, porque colocada nesses termos, a poesia é vista como muito próxima à filosofia como a arte de fabricar conceitos (DELEUZE, 1992), de dar nome aquilo que dele carece, de preencher uma lacuna conceitual contribuindo para a construção coletiva de significados.

Se pensarmos como a possibilidade de contribuir para o arcabouço interpretativo é distribuída de maneira desigual entre os diferentes grupos de indivíduos, devido a preconceitos sociais estruturantes, entenderemos com mais força porque poesia, de fato, não é luxo. A poesia, ao dar nome a ideias ainda não nascidas, como afirma Lorde, consiste em um possível remédio para marginalização hermenêutica de grupos politicamente minoritários (DOTSON, 2018). O título de Lorde aponta para a ideia de resistência a um apagamento das mulheres negras como produtoras de saber: a produção do saber não é, e não pode ser, luxo, no sentido de ser vista como supérflua e nem mesmo é privilégio de uma elite que goze de condições ideais para a produção do saber. Ocupar-se da palavra para falar do mundo, polir as palavras para plasmar outros mundos é, nesse registro, uma atividade universalmente humana e não algo que apenas um seleto grupo faça ou tenha feito. Esse texto ${ }^{1}$ se debruça sobre os versos mágicos de tatiana nascimento e seu conceito de cuíerlombismo como imagem organizadora de um desejo por (afro)futuros.

\section{Quilombismo}

É de outros Nascimentos que tatiana herda o quilombismo como ideia. E da potência confabulativa do encontro com as teorias queer (ou na sua versão latinoamercana: cuír) nasce a noção de queerlombo, ou cuírlombo.

Beatriz Nascimento já havia chamado atenção para o parentesco entre os quilombos como insurreição e os quilombos como organização social dos povos bantus em África (NASCIMENTO, p.119). Pesquisando

1 Este texto surgiu como um dos produtos de um projeto mais amplo, dedicado a aproximar filosofia e poesia escritas por mulheres negras, através da aproximação entre diferentes autoras. O projeto surgiu como iniciação científica no ensino técnico integrado ao ensino médio (PIBIC-EM), em Águas Lindas, município de Goiás que se localiza no entorno do Distrito Federal. Uma comunidade majoritariamente negra e marcada pela gentrificação na capital. 
quilombos no território brasileiro e comparando com as organizações espaciais/econômicas/sociais em Angola, a autora afirma haver entre as duas experiências uma continuidade histórica e cultural e uma similaridade espacial. Ela nos diz que o conceito de quilombo está presente entre os povos bantus, mas que se modificou através dos séculos:

O nome original vem de Angola, que em determinado momento da história da resistência angolana queria dizer acampamento de guerreiros na floresta, administrado por chefes rituais de guerra. (...) Comparando a documentação da história de Angola e da conquista portuguesa na Bacia do Congo, com as fontes que temos, percebe-se essa tradição bantu no que foram os quilombos brasileiros (notadamente Palmares). (NASCIMENTO apud RATTS, 2006, p. 58)

Beatriz Nascimento reconhece que existem continuidades e descontinuidades entre os quilombos angolanos e brasileiros. Mas há em ambos uma raiz comum: a procura por pertencimento a um território, o direito literal à terra, mas o direito simbólico a existência e à construção coletiva de sentidos. A conexão entre quilombo e resistência anti-colonial tem origem no século XIX, segundo Beatriz Nascimento, e a ideia mesma de quilombo passa a alimentar "o sonho de liberdade de milhares de escravos das plantações em São Paulo, mais das vezes através da retórica abolicionista" (NASCIMENTO, 2006. p.122). Beatriz Nascimento aponta que o quilombo se redefine de instituição para símbolo de resistência anti-colonial organizado em torno da "memória e esperança de recuperação do poder usurpado". Ela nos afirma que o quilombo passa a ser pensado em termos de desejo e utopia:

Por tudo isto o quilombo representa um instrumento vigoroso no processo de reconhecimento da identidade negra brasileira para uma maior autoafirmação étnica e nacional. O fato de ter existido como brecha no sistema em que negros estavam moralmente submetidos projeta uma esperança de que instituições semelhantes possam atuar no presente ao lado de várias outras manifestações de reforço à identidade cultural. (NASCIMENTO, 2006. p. 125)

Abdias Nascimento, provocado pela argumentação de Beatriz Nascimento, nos conta que os quilombos são o resultado da exigência vital dos africanos escravizados, da busca pelo resgate de liberdade e dignidade através da fuga e da construção de uma sociedade livre. Para ele, esse modo de organizar-se constituiu uma vivência metódica e constante para os descendentes de africanos que, recusando submeter-se a exploração e violência, buscavam uma outra forma de vida. Para o autor, o quilombismo não aparece apenas nas comunidades escondidas na mata, outras formas de organização comunitária de pessoas negras possuem características de aquilombamento: organizações religiosas, recreativas, esportivas, culturais, irmandades, terreiros, confrarias, afoxés, escolas de samba. Esses dois tipos de quilombo, o quilombo ilegal e os quilombos legalizados:

foram uma unidade, uma única afirmação humana, étnica e cultural, a um tempo integrando uma prática de libertação e assumindo o comando da própria história. A este complexo de significações, a esta práxis afro- brasileira, eu denomino de quilombismo (NASCIMENTO, 1980).

O quilombismo é proposto pelo autor como tática de sobrevivência, como uma forma de se organizar, de mobilização do povo amefricano (para usar o termo usado por Lélia Gonzalez). Abdias Nascimento cita Beatriz Nascimento a dizer que os quilombos foram e ainda são, a despeito de suas diferenças, "um local onde a liberdade era praticada, onde os laços étnicos e ancestrais eram revigorados" (NASCIMENTO, 1979, p. 17 apud NASCIMENTO, 1980).

O autor reforça que quilombo não se reduz a ideia de fuga de escravos, antes, quer apontar para a "reunião fraterna e livre, solidariedade, convivência, comunhão existencial". Na experiência do quilombo o autor 
também encontra a semente de outro sistema econômico: o quilombismo é uma proposta anti-capitalista que nasce da tentativa de adequar o comunitarismo, os princípios de $U_{j a a m a}{ }^{2}$ - a ideia de que uma pessoa se torna pessoa através da comunidade e todas as implicações que isso tem em termos de organização social - à realidade brasileira:

\begin{abstract}
Nem propriedade privada da terra, dos meios de produção e de outros elementos da natureza. Todos os fatores e elementos básicos são de propriedade e uso coletivo. Uma sociedade criativa, no seio da qual o trabalho não se define como uma forma de castigo, opressão ou exploração; o trabalho é antes uma forma de libertação humana que o cidadão desfruta como um direito e uma obrigação social. Liberto da exploração e do jugo embrutecedor da produção tecno-capitalista, a desgraça do trabalhador deixará de ser o sustentáculo de uma sociedade burguesa parasitária que se regozija no ócio de seus jogos e futilidades (NASCIMENTO, 1980).
\end{abstract}

Abdias Nascimento propõe, então, uma revolução quilombista que seja fundamentalmente antirracista, anticapitalista, antilatifundiária, antiimperialista e antineocolonialista. Parte importante do processo de construir o quilombismo é, portanto, reivindicar o direito ao passado, à memória de África que conecta toda a população amefricana. Entender o passado é parte importante do caminho para construção coletiva de um (afro)futuro. $\mathrm{O}$ afrofuturismo de Abdias do Nascimento se dá através de um esforço de revisitar o passado.

Em outro sentido se movem Kênia Freitas e José Messias que pensando sobre afrofuturismo se perguntam: "como a comunidade negra diaspórica que teve deliberadamente o nosso passado roubado e apagado pela escravidão consegue, sem esse acervo de imagens, vislumbrar futuros?" (FREITAS; MESSIAS, 2018, p. 406). Samuel Delany, escritor de ficção científica estadunidense, um dos grandes nomes da chamada black scifi também discorre sobre a conexão entre passado e futuro negros (DERY, 1997). Delany diz que a humanidade precisa de imagens do amanhã, e que as pessoas negras na diáspora precisam de tais imagens ainda mais, uma vez que a experiência da escravização negou a elas um acesso a sua tradição. Delany, aponta que se existe um afrofuturismo ele não emerge apenas da ficção científica, mas de outras fontes. Para ele, a exclusão tecnológica e o uso de artefatos técnicos para outros fins está na base da invenção, por garotos negros da periferia, do rap enquanto movimento cultural. É essa relação de apropriação criativa da tecnologia, bem como o resgate de tecnologias ancestrais que estaria na base de um afrofuturismo, segundo Delany.

Apropriação criativa e disruptiva da técnica e tecnologia ancestral: duas possibilidades de pensar afrofuturos, na literatura, nas artes, com as palavras. Ressalte-se, nesse sentido, o caráter afrofuturista do quilombismo de Beatriz e Abdias Nascimento que enxergam no quilombo a tecnologia ancestral de que o futuro pode ser feito. O quilombo, em contraste com o gueto que supõe impotência, aparece como espaço de enfrentamento, como experiência de contraviver o sistema (EVARISTO, 2010, p. 139). A literatura de aquilombamento seria esse espaço de manter e difundir a memória e identidade amefricana, lugar para falar de si, tomando para si o direito a nomear-se e dizer de si, abrindo outras histórias, em desafio ao ponto de vista da imaginação colonial.

Para Evaristo, a palavra poética é um modo de narrar o mundo que habitamos e de revelar o desejo utópico de construção de um novo mundo, a utopia como descontentamento, como elemento fundamental para organizar a revolta enquanto potência. É seguindo esses passos que tatiana nascimento se propõe a pensar o cuírlombo da palavra, a poesia LGBTQI negra como esse construir utópico. africanas como respeito mútuo, propriedade comunal e trabalho comunal. Entretanto, os autores sublinham que é um desafio expandir esses valores tradicionais a sociedade moderna pós-colonial 


\section{0 cuírlombo da palaura}

cola-velcro - é da diáspora

(...)

o continente que inventou o mundo

inventou tb muitos jeitos de e

star no mundo. que

"gente é pra brilhar

não para morrer"

sem nome

[trecho de manifesta queerlomba, ou tecnologia / ancestral/

de cural amor/ y de / prazer, de tatiana nascimento]

Em cuírlombismo literário, seu ensaio de 2019, tatiana nascimento propõe uma poética negra LGBTQI+ que desorbite a dor e a denúncia como principal elemento na tomada da palavra. No ensaio também propõe revisitar alguns $i_{t a n^{3}}$ para neles buscar uma ancestralidade cuír, desafiando uma visão monológica de uma África mítica e heteronormativa. Desorbitância e revisita se entrelaçam no texto rumo a construção a-tópica (no sentido do ainda sem lugar e sem tempo) de uma abertura, de uma tessitura do futuro. Não se trata de anseio por um retorno a uma tradição. Mas sim de uma busca por olhar o passado com olhos renovados. Como em Abdias Nascimento, trata-se de um esforço por autodefinição, que abandone a definição da experiência de ser negra pela escravização. A referência à ancestralidade é, ela mesma, a matéria com a qual a poeta constrói uma ponte para um lesbo(afro)futuro. O quilombo, que também inicia com a fuga e o abandono de uma estrutura opressiva e floresce na recriação de outras formas de vida, na experimentação da liberdade, é ao mesmo tempo metáfora e método.

Mas seu quilombismo se desloca para um cuíerlombismo, que segundo ela é:

um achar-se ao achar a encruzilhada - ou, outra metáfora de Exu, deus da comunicação, num jogo curto de palavras declamando autoconstituição que montei a partir do verbo preto, ou empretecido. na segunda edição do livro, reconfigurei "queerlombismo" como "cuíerlombismo", me apropriando da artimanha sudaca de tradução-retomada de termos gringos para que tenham mais nossa cara ou u: recurso de descolonização conceitual que tem explorado a morfologia de um termo gringo pra reassentar sua semântica em bases mais latinas, pelo processo de rasurar/reescrever esse conceito-chave, "teoria queer/ queer studies", sobre o qual tantas disputas têm sido feitas dum jeito que tenha a nossa (múltipla) cara: cuír, kuír, cuia (NASCIMENTO, 2018).

A referência ancestral aparece não apenas nas leituras de intelectuais negras, na genealogia da ideia que a poeta faz, mas também nas releituras de itan. A poeta discute dois itan buscando neste acesso mitologizado ao passado encontrar elementos que resistam a heterossexualidade compulsória. No itan "Oxum seduz Iansã" relatado por Reginaldo Prandi, lemos:

3 "Itan é uma palavra iorubá que significa história, qualquer história; um conto. De um modo mais específico, itan são histórias do sistema nagô de consultas às divindades” (PÓVOAS apud SOUZA; SOUZA, 2019). 
Uma vez Oxum passou pela casa de Iansã e a viu na porta

Ela era linda, atraente, elegante

Oxum então pensou: "Vou me deitar com ela"

Oxum era muito decidida e muito independente

(...)

No começo Iansã não se deu conta do assédio,

Mas depois acabou por se entregar.

Mas logo Oxum se dispôs a nova conquista

E Iansã a procurou para castiga-la.

Oxum teve de fugir para dentro do rio,

Lá se escondeu e lá vive até hoje.

(PRANDI, 2001, p. 326)

Nascimento discute que nesse itan a relação entre as Iansã e Oxum acabam por resultar na conexão da última a uma de suas principais características: seu domínio sobre as águas doces. É esse encontro que faz de Oxum, ao menos nessa narrativa (que não pretende explicar o todo, mas apenas uma pequena parte), quem ela é. As metáforas sobre água se fazem presentes na poesia de tatiana nascimento, muitas vezes relacionadas a lesbiandade.

A poeta encontra nesse itan, portanto, recursos imagéticos para sua poesia e fonte para afirmar uma certa ancestralidade da dissidência sexual, resistindo a uma visão heteronormativa de uma África monolítica. Como em Nossos passos vem de longe de Jurema Werneck, outras histórias de África, são fontes para articular resistência ao modelo colonial racista, sexista e lgbtqifóbico. Esse olhar para o passado que tatiana faz não é um ato nostálgico de restauração. É olhar para um processo que foi interrompido e desenraizado pela colonização. E buscar nele, alimento para outras futuridades. A poeta afirma que essa busca tem a ver com entender que o racismo não é a origem das pessoas negras na diáspora: "sempre fomos mais e antes". Seus passos vem de longe: recontar é recriar.

Esse recontar é atento as conexões e desconexões coloniais entre raça, classe, gênero e orientação sexual. Como o racismo, a colonização é também heterocissexista. Informada pela discussão descolonial, tatiana afirma que as expectativas sexuais sobre corpos negros é um dos pilares do racismo e, assim, a poeta escava um passado pré-colonial de dissidência sexual como método para pensar o futuro que busca plasmar. Dessa forma esse recontar é um recriar transformador, que busca não sufocar as "raízes nutrizes da assunção dessa ancestralidade das dissidências sexuais e/ou de gênero" (NASCIMENTO, p. 10), por um lado, e se projetar para o futuro que deve ser "brilhantemente negro":

Forjo desde meu lugar afrodiaspórico sexual-dissidente o conceito de cuirlombismo literário. Reagir a dor é ainda recontar histórias. Falar dor nos permite buscar cura (...) sentir a ferida colonial, pensar: como curar esse grande machucado íntimo, coletivo, antigo, renitente? Mesmo que denunciar o racismo heterocissexista seja uma necessidade constante de afirmação de existências negras lgbtqi, temos mais que denúncias a fazer, especialmente pela nossa poesia, que se conecta a um projeto epistêmico negro-sexual-dissidente atravessado por disputas narrativas. (NASCIMENTO, 2019, p. 18).

A literatura aparece, então como literacura. Como bálsamo para a ferida colonial, como espaço de organização e experimentação utópica. Através da literatura outros mundos são inventados, quilombos de sonho e afeto podem ser plasmados ou, nas palavras da poeta "fundamos nosso lugar no dizer" (NASCIMENTO, 2019 p. 24). A poeta vê esse movimento de plasmar mundos como um exercício de visão que inaugura futuros. 


\section{Conclusão}

A poeta tatiana nascimento se inscreve numa linhagem de intelectuais negras brasileiras que buscaram pensar o quilombo como expressão cultural de resistência negra e abertura para um futuro brilhantemente negro. Num exercício de pensar a marca colonial da heterossexualidade compulsória, a poeta busca na ancestralidade e nas cosmovisões do candomblé exemplos de dissidência sexual - a que identifica como tecnologia ancestral afrofuturista - que alimentam sua criação de sentidos e mundos através da poesia. Assim, o cuírlombismo aparece como prática literária de construção de resistência cuír e negra ao racismo heterossexualizante. Se para Beatriz Nascimento a terra era seu quilombo, para tatiana nascimento é de palavras que o cuírlombo pode ser construído - poesia não é luxo, é a ocupação do espaço, a reivindicação do poder de dar sentido ao mundo.

\section{Referências}

DERY, Mark. Black to the Future: Interviews with Samuel R. Delany, Greg Tate, and Tricia Rose. In: DERY, Mark (ed). Flame wars: the discourse of cyberculture Duke University, 1997.

DOTSON, Kristie. In search of Tanzania: are effective epistemic practices sufficient for just epistemic practices? Southern Journal of Philosophy, Vol. XLVl, 2018, p. 52-64.

EVARISTO, Conceição. Literatura negra: uma voz quilombola na literatura brasileira. In: PEREIRA, Edimilson de Almeida (Org.). Um tigre na floresta de signos: estudos sobre poesia e demandas sociais no Brasil. Belo Horizonte: Mazza, 2010.

FREITAS, Kenia; MESSIAS, José. O futuro será negro ou não será: Afrofuturismo versus Afropessimismo - as distopias do presente. Imagofagia: Revista de La Asociación Argentina de Estudios de Cine y Audiovisual, Argentina, v. 1, n. 17, abr. 2018, p.402-424. Disponível em: <http://asaeca.org/imagofagia/index.php/imagofagia/article/view/1535>. Acesso em: 30 set. 2018.

IBHAWOH, Bonny; DIBUA, J. I. Deconstructing Ujamaa: The Legacy of Julius Nyerere in the Quest for Social and Economic Development in Africa. African Journal of Political Science, vol. 8, no. 1, 2003.

LORDE, Audre. Poesia não é Luxo. NASCIMENTO, tatiana. (Trad.) Disponível em: <https://traduzidas.wordpress. com/2013/07/13/poesia-nao-e-um-luxo-de- audre-lorde/> Acesso em: 25 maio 2021.

LORDE, Audre. I am your Sister: Black Women Organizing Across Sexualities. Boston: Kitchen Table, Women of Color Press, 1985.

NASCIMENTO, Abdias. Quilombismo: um conceito emergente do processo histórico-cultural da população afro-brasileira. Uma proposta do autor aos seus irmãos e irmãs afrodescendentes no Brasil e nas Américas, em trabalho apresentado ao 2o Congresso de Cultura Negra das Américas, Panamá, 1980.

NASCIMENTO, Beatriz. O conceito de quilombo e a resistência cultural negra. In: RATTS, Alex. Eu sou Atlântica: sobre a trajetória de vida de Beatriz Nascimento. São Paulo: Instituto Kuanza, 2006.

NASCIMENTO, Tatiana. Letramento e tradução no espelho de Oxum: teoria lésbica negra em auto/re/conhecimentos. Tese [doutorado]. Florianópolis: Universidade Federal de Santa Catarina, 2014.

NASCIMENTO, Tatiana. da palavra queerlombo ao cuíerlombo da palavra. 2018. Disponível em $<$ https://palavrapreta.wordpress.com/2018/03/12/cuierlombismo/> Acesso em: 05 de setembro de 2020.

NASCIMENTO, Tatiana. Cuírlombismo Literário: poesia negra LGBTQI desorbitando o paradigma da dor. Série Pandemia. N-1 Edições. Outubro de 2019.

NASCIMENTO, Tatiana. Lundu. Brasília: Padê Editorial, 2016.

NASCIMENTO, Tatiana. 07 notas sobre o apocalipse ou poemas para o fim do mundo. Rio de Janeiro: Garupa e Kzal, 2019.

NASCIMENTO, Tatiana. Diz/topias: que territórios criam as línguas da poesia lésbica negra? Suplemento Pernambuco, no. 170, Abril de 2020, p. 12-17.

PRANDI, Reginaldo. Mitologia dos Orixás. São Paulo: Companhia das Letras, 2001.

RATTS, Alex. A Terra é o meu quilombo - Terra, território, territorialidade. In: RATTS, Alex. Eu sou Atlântica: sobre a trajetória de vida de Beatriz Nascimento. São Paulo: Instituto Kuanza, 2006. 